\title{
Effect of wetting method on the broiler transport in Brazilian Northeast
}

Daniel Gurgel Pinheiro - José Antonio Delfino Barbosa Filho • Nítalo André Farias Machado iD

\section{DG Pinheiro}

Federal Institute of Science and Technology of Ceará, Av. Treze de Maio, 2081, Benfica, CEP 60040-531, Fortaleza, Ceará, Brazil.

email: nitalo-farias@hotmail.com

\author{
JAD Barbosa Filho - NAF Machado (Corresponding \\ author) \\ Department of Agricultural Engineering, Federal University \\ of Ceará, Av. Mister Hull, s/n, Pici, Bloco 804, CEP 60455- \\ 760, Fortaleza, Ceará, Brazil.
}

Received: March 23, 2020 • Accepted: April 07, 2020 • Published Online: April 21, 2020

\begin{abstract}
The aim of this study was to evaluate the efficiency of the load wetting method to attenuate the ambience of the load the transport of broilers. Fourteen commercial consignments were monitored over a $25 \mathrm{~km}$ route, and in seven of these, the load wetting was carried (LW) out while in the other seven no wetting was done (LD). The temperatures of the side, top and rear load boxes were analyzed by infrared thermography. The central row load boxes were evaluated by geostatistics, using temperature variability (TA), relative humidity $(\mathrm{RH})$ and the enthalpy comfort index (ECI). The mean was compared by Student's t-test $(P<0.05)$. The results showed that load wetting has a momentary effect $(P<0.05)$. The boxes located in the central rows in the LW showed a higher $(P<0.05)$ ECI compared to those in the LD. In addition, areas classified as lethal were formed in the LW. In conclusion, load wetting was not an efficient method to attenuate the ambience of load during the commercial transport of broilers, as it only has momentary and transient effects.
\end{abstract}

Keywords: ambience, animal welfare, bioclimatology, preslaughter, thermography

\section{Introduction}

The broilers' transport to the slaughterhouse is a complex operation from the animal welfare point of view (Chauvin et al 2010; Spurio et al 2016). Broilers' transport are currently under investigation with a particular focus on design and dimensions of commercially available transport crates (Vinco et al 2016) because the temperature-relative humidity ratio and the thermal gradients generated between the transport boxes and the external environment have been pointed out by previous studies as the main cause for the socalled "Dead on Arrival" (Mitchell and Kettlewell, 1994; Hunter et al 1997; Kettlewell et al 2001).

Stress factors during transport increase the mortality rates of the broilers because they affect their well-being. High temperatures associated with large variations of relative humidity and deficiency in air circulation can cause significant losses in the transport of live broilers (Barbosa-Filho et al 2014). Besides being a serious animal welfare problem, it is one of the main sources of losses for the broilers industry that is usually neglected by both producers and carriers (BarbosaFilho et al 2009; Spurio et al 2016).

According to Rui et al (2011), load wetting is a very widespread practice in the broiler sector, especially in tropical regions. This practice seeks to reduce the temperature of the load and thus reduce the impacts caused by thermal stress and, consequently, the mortality rate of the broilers 'during transportation. However, it is usually carried out without following any norms. In this scenario, the infrared thermography can provide important information on the ambience of the load. The thermal imaging obtained give the possibility of target surface temperature mapping (SouzaJunior et al 2019; Rocha et al 2019; Lima et al 2019).

The high relative humidity in the air may reduce the heat exchange capacity of broilers, so the study of the practice of load wetting is warranted. Thus, this research sought to evaluate the efficiency of the load wetting method to attenuate the ambience of the load the transport of broilers.

\section{Materials and Methods}

\section{Localization and logistics}

The experiment was carried out with a company in the metropolitan region of Fortaleza, Ceará, Brazil. Fourteen commercial consignments were monitored over a $25 \mathrm{~km}$ route, and in seven of these, the load wetting was carried out while in the other seven no wetting was done. None of the experiments interfered with the usual operations of the company. The experimental procedures were performed with the consent of the Animal Ethics Committee of the Federal University of Ceará. 
Ross broilers that were 42 days old, with a mean weight of $3.50 \pm 0.90 \mathrm{~kg}$ were transported. The truck used was a Ford ${ }^{\circledR}$ Load 1519. The broilers were transported in boxes of highdensity polyethylene with protection against solar rays with minimal dimensions of $32 \times 56 \times 76 \mathrm{~cm}$. Each box held six broilers, and the load consisted of three horizontal rows of thirteen boxes and nine vertical layers of boxes, totaling three hundred and fifty-one boxes.

Load wetting was performed as the boxes containing the live chickens were being loading onto the truck or more precisely when the truck was half loaded. At that point, an employee started the wetting process at the top of the load with a one-inch-diameter hose. The water used was from an artesian well and stored in 5,000 L water tanks. The water had an average temperature of $19^{\circ} \mathrm{C}$ and the average consumption of each wetting per truckload was $2,200 \pm 300 \mathrm{~L}$.

\section{Data Collection}

Figure 1 shows the general data acquisition flowchart. The temperatures of all the external boxes (left and right sides, top and back) were measured immediately before and after load wetting and again 10 minutes (Figure 2) after load wetting. For these measurements, a 4800-pixel thermal imager 4800 pixel thermal imager $\left(\right.$ Fluke $^{\circledR}$ model TiS10, Everett, WA, USA), at a distance of $1.5 \mathrm{~m}$; the emissivity was set for biological tissues (0.98). The thermograms were analyzed by software Connect ${ }^{\mathbb{R}}$.

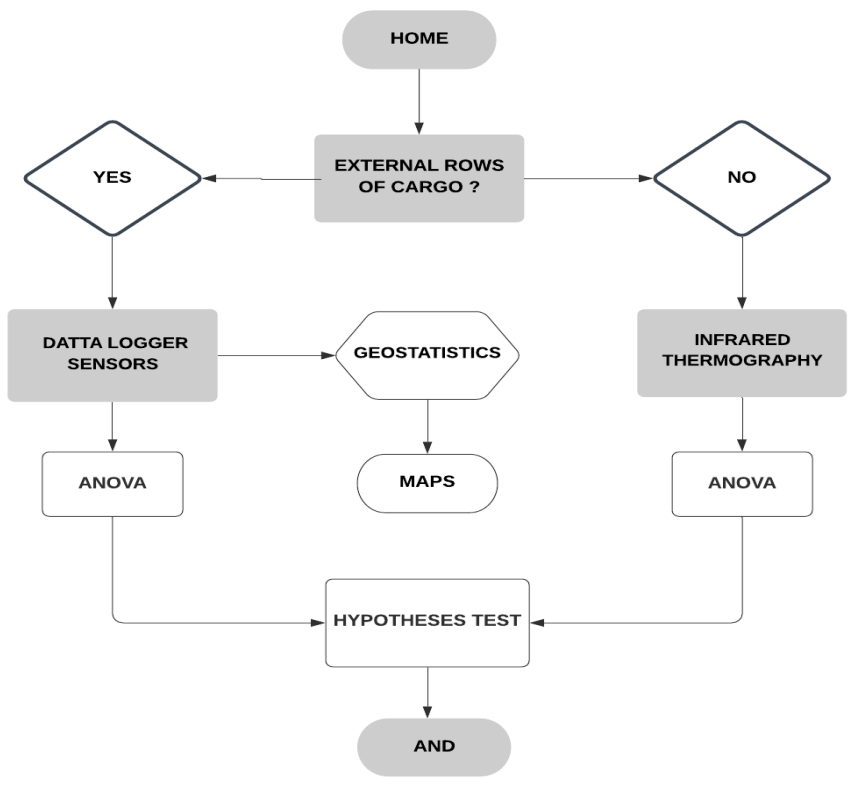

Figure 1 Data collection and analysis flowchart.
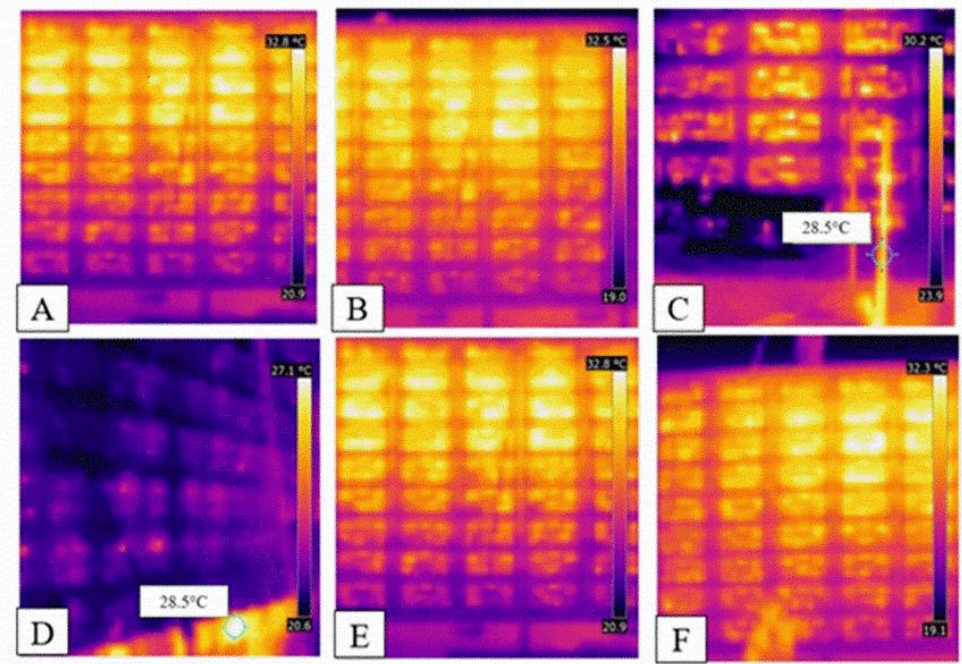

Figure 2 Thermograms of left and right sides of the load before (A and B), just after (C and D) and 10 minutes after load wetting (E and F). 
The heat transferred by convection up a vertical column ( 9 boxes) was calculated using Equation (1) as proposed by Çengel and Ghajar (2012). The central row of the load was analyzed by measuring the air temperature (TA) and relative humidity $(\mathrm{RH})$ using 18 Datta logger sensors (Onset ${ }^{\circledR}$, model U23-001 HOBO ${ }^{\circledR}$ Pro v2, Cape Cod, Massachusetts, USA) programmed for collection data every minute, spatially distributed according Barbosa-Filho (2009).

$\mathrm{Q}=\mathrm{hA}(\mathrm{Ts}-\mathrm{T} ¥)$

where: $\mathrm{Q}$ is the heat transfer rate in Ws; Ts is the surface temperature in $\mathrm{K}$; $\mathrm{T} ¥$ is the fluid temperature in $\mathrm{K}$; $\mathrm{A}$ is the surface area in $\mathrm{m}^{2} ; \mathrm{h}$ is the $50 \mathrm{~W} / \mathrm{m}^{2} \mathrm{~K}$ (convection heat transfer coefficient).

The TA and RH data were used to calculate the Enthalpy Comfort Index (ECI) following Equation 2, as proposed by Rodrigues et al (2011). The different comfort zones used were: comfortable (ECI: 37.40 to $52.10 \mathrm{Kj} / \mathrm{Kg}$ dry air), alert (ECI: 52.20 to $63.30 \mathrm{Kj} / \mathrm{Kg}$ dry air), critical (ECI: 63.10 to $72.60 \mathrm{Kj} / \mathrm{Kg}$ of dry air) and lethal (ECI: 72.70 to $106.00 \mathrm{Kj} / \mathrm{Kg}$ dry air) by Barbosa-Filho et al (2009). Other researchers in tropical regions have used these zones (Barbosa-Filho et al 2014; Queiroz et al 2017).

$\mathrm{ECI}=1.006 . \mathrm{TA}+\frac{\mathrm{UR}}{\mathrm{Pb}} \cdot 10^{7.5 \mathrm{TA}(237.3+\mathrm{TA})^{-1}} \cdot(71.28+0.052 \mathrm{TA})$

where: $\mathrm{ECI}$ is the enthalpy comfort index in $\mathrm{Kj} / \mathrm{Kg}$ dry air; TA: air temperature in ${ }^{\circ} \mathrm{C}$; $\mathrm{RH}$ is the relative humidity in $\%$; $\mathrm{BP}$ is local barometric pressure $\mathrm{mmHg}$.

\section{Statistical analyzes}

The values obtained from the temperature the load by infrared thermography, TA, RH and ECI of the central row of the wet and dry loads were submitted the ANOVA and compared by the Student's t-test $(P<0.05)$. The statistical model used was Yej $=\mu+\mathrm{Te}+\mathrm{Ej}$; where Yej $=$ is the dependent variable; $\mu$ is the effect of the overall mean; Te is treatment effect (with or without wetting method); $\mathrm{Ej}$ is the effect of random errors associated with observations. The variability of TA, RH and ECI of the central row was computed using ordinary kriging interpolation (Eq. 3) with Surfer ${ }^{\circledR}$ (Golden Software, Inc.), Version 10.

$\bar{\gamma}(h)=\frac{1}{2 \mathrm{n}_{(\mathrm{k})}} \sum_{\mathrm{i}=1}^{\mathrm{N}(\mathrm{k})}\left[\mathrm{Z}\left(\mathrm{s}_{\mathrm{i}}\right)-\mathrm{Z}\left(\mathrm{S}_{\mathrm{i}}+\mathrm{h}\right)\right]^{2}$

where: $\mathrm{h}$ is the distance between measurements; $\mathrm{N}(\mathrm{k})$ is the number of experimental pairs of measured data of $Z$ (xi) and $\mathrm{Z}(\mathrm{si}+\mathrm{h}) ; \mathrm{Z}(\mathrm{si})$ is the value of the variable for the position si *not estimated (true) considered as a random variable, function of the sampling position $\mathrm{x} ; \mathrm{Z}(\mathrm{si}+\mathrm{h})$ : value of the same variable in the position $\mathrm{si}+\mathrm{h}$ in any direction.

\section{Results}

The high amount of heat energy released by the broilers inside the boxes is visible before load wetting (Figure $2 \mathrm{~A}$ and B). There was a mean superficial temperature variation from $22.9{ }^{\circ} \mathrm{C}$ to $31.1^{\circ} \mathrm{C}$ before load wetting (Figure 3), and that most of the boxes are above the critical temperature limit, 24 ${ }^{\circ} \mathrm{C}$ by Macari and Furlan (2001).

Shortly after load wetting, there was a drop $(P<0.05)$ in the temperature profile of the boxes with mean temperature values of $23.5{ }^{\circ} \mathrm{C}$, which is within the comfort zone (Figure 3 ), observed of the Figure $2 \mathrm{C}$ and $\mathrm{D}$. However, 10 minutes after load wetting, the temperatures increase $(P<0.05)$ and stabilized again in $26.8^{\circ} \mathrm{C}$ (Figure 3), as shown in Figures $2 \mathrm{E}$ and $\mathrm{F}$.

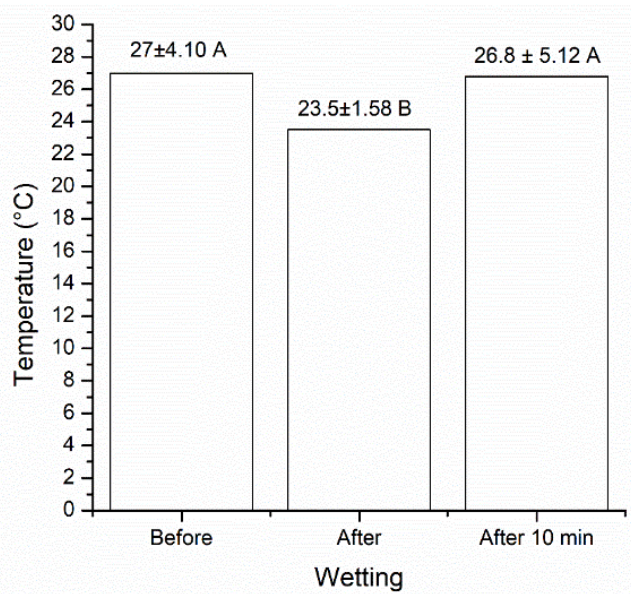

Figure 3 Average box superficial temperature values before, after and 10 after wetting of load. Averages followed by different letters, are statistically different by Student's t-test $(P<0.05)$.

The results obtained showed that TA along the central row was above the upper limit of comfort for broilers $\left(24^{\circ} \mathrm{C}\right.$; Macari and Furlan 2001), with (LW) and without wetting of the load (DL), (Figure 4 and 5, respectively). Higher temperatures (around $30{ }^{\circ} \mathrm{C}$ ) along the central row were obtained in DL, which concentrated at the back of the truck (about $32{ }^{\circ} \mathrm{C}$ ) (Figure 5).

The spatial distribution of RH along the central row in LW has high RH values, greater than $90 \%$. Much of the load had values that exceeded the upper comfort limit established for RH (> 65\% - Macari and Furlan 2001). The ECI values had an irregular distribution, with points of maximum concentration between the frontal and the central region of the load (Figure 5). These points with high ECI values were classified as lethal ( 87 to $92 \mathrm{KJ} / \mathrm{Kg}$ dry air) by Barbosa Filho et al (2009). 

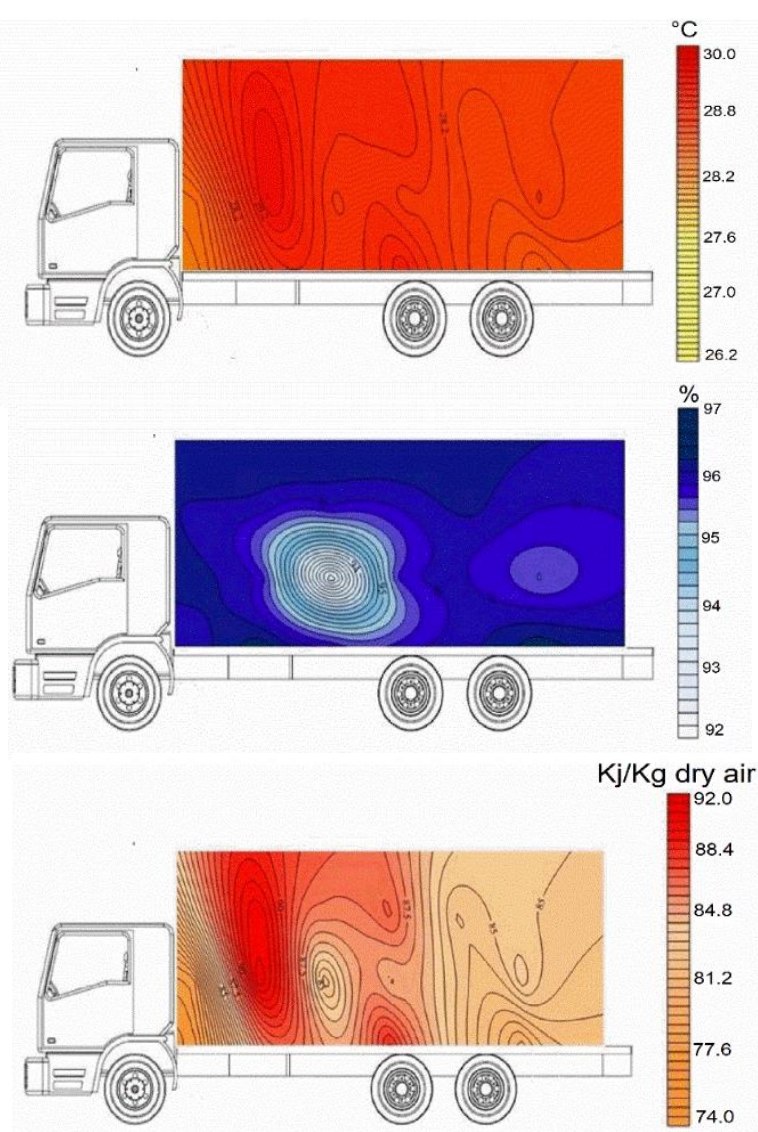

Figure 4 Spatial variability maps of temperature, relative humidity, and Enthalpy Comfort Index of the central row of the load with load wetting (LW).

The spatial distribution of the ECI in LD (Figure 6) showed that the microclimate presented a situation of discomfort with values between the regions classified as critical $(63.1$ - $72.6 \mathrm{Kj} / \mathrm{Kg}$ dry air) and lethal (72.6 - 106.0 $\mathrm{Kj} / \mathrm{Kg}$ dry air) by Barbosa Filho et al (2009), as was also observed in the wet load. However, most of the boxes located in the central region of the load presented values classified as "critical". The boxes with the worst microclimate conditions were concentrated in the rear of the truck, with values classified as lethal. In general, on arrival at the slaughterhouse, the RH was higher $(P<0.05)$ in the load LW, but presented lower $(P<0.05)$ TA (Figure 6$)$. However, there was a higher $(P<0.05)$ average of the IEC in the load LW (Figure 7).

\section{Discussion}

Our results demonstrate that in some cases, wetting of the load is not an efficient practice. The thermograms before load wetting (Figure $2 \mathrm{~A}$ and B) clearly demonstrate the high energy released by the broilers inside the boxes. Convective heat transfer between the boxes was estimated at $9.919 \mathrm{~W}(\mathrm{~J} / \mathrm{s})$ in the present study. This value is equivalent to the average power of $10,000100 \mathrm{~W}$ incandescent bulbs or the average power of 10 domestic electric ironing irons.
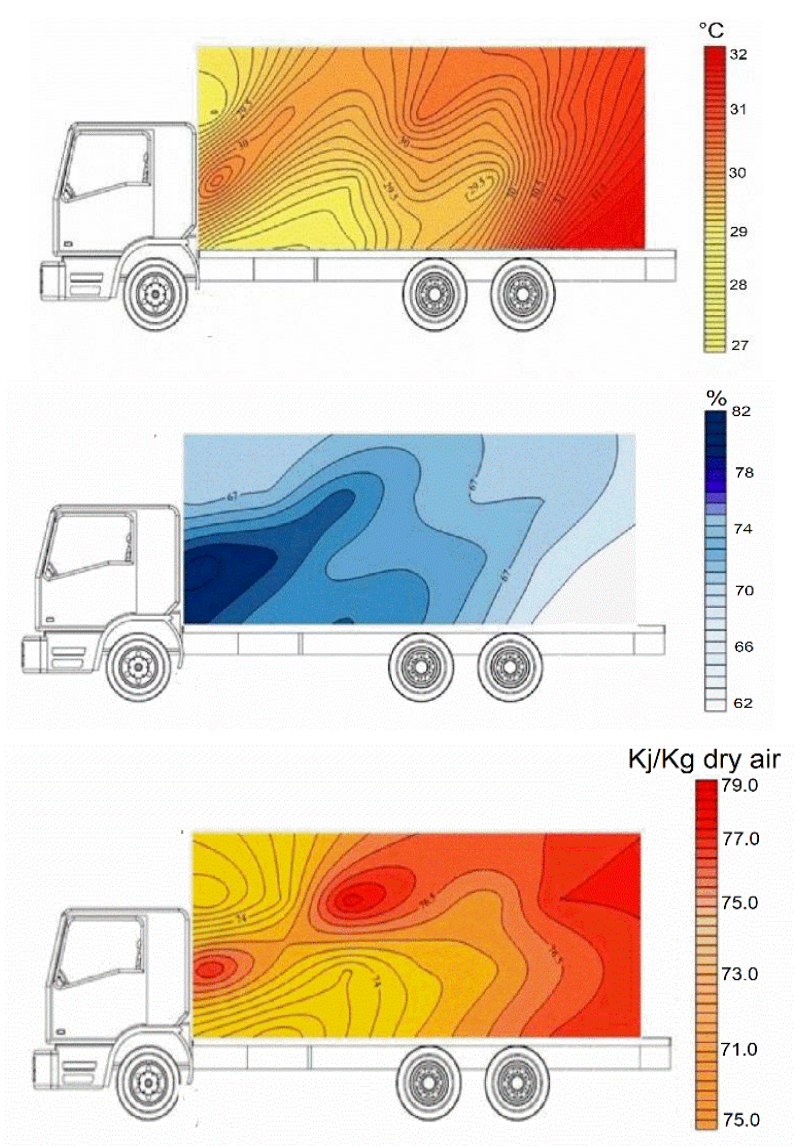

Figure 5 Spatial variability maps of temperature, relative humidity, and Enthalpy Comfort Index of the central row of the load without wetting (LD).

Load wetting produced a substantial reduction in temperatures in the lateral rows, within the comfort zone, which varies from 20 to $24{ }^{\circ} \mathrm{C}$ (Macari and Furlan 2001), as shown in Figure 3. The water flow between the boxes promotes convective thermal changes; during this process, there is a $9.5^{\circ} \mathrm{C}$ increase in the water temperature. The inserts in Figures $2 \mathrm{C}$ and $\mathrm{D}$ highlight the temperature of the water after the thermal exchange with the broilers, which went from $19{ }^{\circ} \mathrm{C}$ to $28.5^{\circ} \mathrm{C}$.

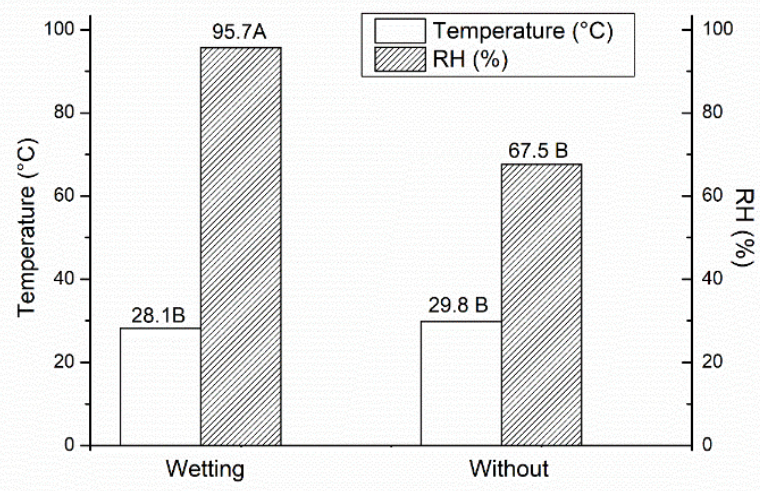

Figure 6 Average values of temperature and relative humidity of the central row of the load with (LW) and without wetting (LD). Averages followed by different letters, are statistically different by Student's t-test $(P<0.05)$. 
However, 10 minutes after load wetting, the thermograms (Figures 2 and 3) displayed similar temperatures to those presented before load wetting; this demonstrates that under commercial conditions the load wetting practice presented a reduction of the temperature inside the boxes only for a short period of time.

In the United Kingdom, Hunter et al (1999) found that the load wetting method may cause acute hypothermia in broilers. The authors also reported the inefficiency of the thermoregulatory mechanisms of the broilers when the exposure to temperatures ranging from -4 to $12{ }^{\circ} \mathrm{C}$. In Brazil, Barbosa Filho et al (2009) carried out a detailed study on the transportation of broilers and provided some results that prove to the reversal of the stress of heat for the stress of cold, mainly due to the practice of load wetting, when performed without standards.

In relation to the central load rows on the trucks, the highest temperatures were recorded in LD (Figure 5). This suggests that the magnitude of the thermal changes due to water with the boxes caused a reduction in the temperature during transport. However, the $\mathrm{RH}$ values of the load change due to load wetting, with values ranging from 62 to $78 \%$ in LD (Figure 5) for values ranging from 92 to $97 \%$ in $\mathrm{WL}$ (Figure 4), which can drastically affect the environmental condition of the load and the thermal exchange system of the broilers. This result can be explained by the fact that during the load wetting there is an accumulation of water in the boxes, especially those on the bottom row in direct contact with the truck as well as those in the central rows (Pinheiro 2015).

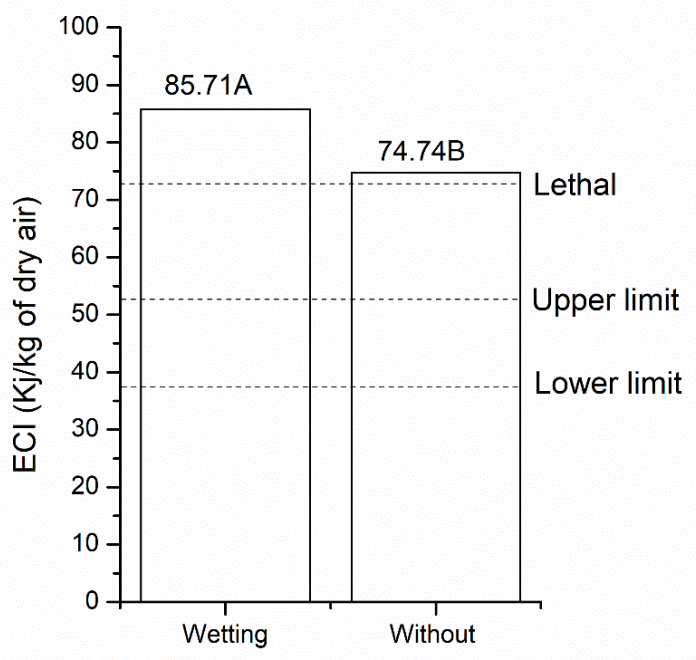

Figure 7 Average values of Enthalpy Comfort Index of the central row of the load with (LW) and without wetting (LD). Averages followed by different letters, are statistically different by Student's ttest $(P<0.05)$.

In the LW, there was a greater accumulation of UR when compared to LD (Figure 6). This excess of water in the boxes, in turn, promotes the formation of a supersaturated atmosphere of water vapor (Webster et al 1992), which explains the higher average value $(P<0.05)$ of the ECI in LW (Figure 7). Furthermore, there is a greater formation of zones classified as "lethal" for broilers ( 87 to $92 \mathrm{Kj} / \mathrm{Kg}$ of dry air) in the loads that received wetting (Figure 4). This also drastically reduces the heat loss by evaporation, which is the main mechanism (Silva et al 2007), and thus compromises the thermal comfort and welfare of the broilers.

The connection of higher points of $\mathrm{RH}$ and internal airflow patterns of the load to the heat cores during the transport of broilers has already been reported in other studies (Mitchell et al 1992 and Kettlewell et al 1993). Furthermore, other studies have also demonstrated a relationship between the distribution of dead broilers and areas of greater discomfort in the load LW (Hunter et al 1997; Barbosa-Filho et al 2009).

Possibly, the main reason for high RH values is the box designer and load layout, which promotes points where accumulation occurs. The ventilation deficiency is, from an environmental point of view, the variable that most influences the points of greatest thermal load by the accumulation of $\mathrm{RH}$, (Gilkeson et al 2012; Gilkeson et al 2016) because ventilation promotes air renewal. Future studies can be developed to assess conditions in more detail.

\section{Conclusions}

The load wetting was not an efficient method to attenuate the ambience of load during the commercial transport of broilers, as it only has momentary and transient effects.

\section{Conflict of Interest}

The authors declare no conflict of interest.

\section{References}

Barbosa-Filho JAD, Queiroz ML, Brasil DF, Vieira FMC, Silva IJ (2014) Transport of broilers: load microclimate during Brazilian summer. Engenharia Agrícola 34:405-421.

Barbosa-Filho JAD, Vieira FMC, Silva IJO, Garcia DB, Silva MAN, Fonseca BHF (2009) Transporte de frangos: caracterização do microclima na carga durante o inverno. Revista Brasileira de Zootecnia 38:2442-2446.

Çengel YA and Ghajar A (2012) Heat transfer and mass: a practical approach. $4^{\mathrm{a}}$ edn. AMG, New York, USA.

Gilkeson CA, Thompson HM, Wilson MCT, Gaskell PH (2016) Quantifying passive ventilation within small livestock trailers using Computational Fluid Dynamic. Computers and Electronics in Agriculture 124:84-99.

Gilkeson CA, Thompson HM, Wilson MCT, Gaskell PH, Barnard RH (2009) An experimental and computational study of the aerodynamic and passive ventilation characteristics of small livestock trailers. Journal of Wind Engineering and Industrial Aerodynamics 97:415-425. 
Hunter RR, Mitchell MA, Carlisle AJ (1999) Wetting of broilers during cold weather transport: a major source of physiological stress? British Poultry Science 40:48-49.

Hunter RR, Mitchell MA, Matheu C. (1997) Distribution of "Dead on Arrivals" within the bio-load on commercial broiler transporters: correlation with climatic conditions and ventilation regimen. British Poultry Science 38:7-9.

Kettlewell PJ, Hoxey RP, Hampson JC, Green NR, Vale BM, Mitchell MA (2001) Design and Operation of a Prototype Mechanical Ventilation System for Livestock Transport Vehicles. Journal of Agricultural Engineering Research 79:429-439.

Kettlewell PJ, Mitchell MA, Meehan, A (1993) The distribution of thermal loads within poultry transport vehicles. Agricultural Engineer 48:26-30.

Lima LR, Barbosa-Filho JAD, Freitas ER, Souza DH, Viana VSS, Machado, NAF, Nepomuceno RC (2019) Effect of Different Breeding Densities and Inclusion of Soybean Oil on Performance, Carcass Trait and Heat Loss in Meat Quails. Journal of Agricultural Science 11-130-138.

Macari M and Furlan RL (2001) Ambience in poultry production in tropical climate. FUNEP, Piracicaba.

Mitchell MA and Kettlewell PJ (1994) Road transportation of broiler-chickens - induction of physiological stress. World's Poultry Science Journal 50:57-59.

Mitchell MA, Kettlewell PJ, Maxwell MH (1992) Indicators of physiological stress in broiler chickens during road transportation. Animal Welfare 1:91-103.

Queiroz MLV, Barbosa-Filho JAD, Sales FAL, Lima LR, Duarte LM (2017) Spatial variability in a broiler shed environment with fogging system. Ciência Agronômica 48:586-595.
Rocha LM, Devillers N, Maldague X, Kabemba FK, Fleuret J, Guay F, Faucitano L (2019) Validation of Anatomical Sites for the Measurement of Infrared Body Surface Temperature Variation in Response to Handling and Transport. Animals 9:1-18.

Rodrigues VC, Silva IJ, Vieira FM, Nascimento ST (2011) A correct enthalpy relationship as thermal comfort index for livestock, International Journal Biometeorology 55:455-459.

Rui BR, Angrimani DSR, Silva MAA (2011) Critical points in the pre-slaughter management of broiler: feed withdrawal, capture and catching, transport and lairage time in the plant. Ciência Rural 42:17.

Silva MAN, Barbosa-Filho JAD, Silva CJM, Rosário JMS, Silva IJO, Coelho AUD, Savino VJM (2007) Evaluation of thermal stress in simulated condition of transportation on broiler chickens. Revista Brasileira de Zootecnia 36:1126-1130.

Souza-Junior JBF, El-Sabrout K, Arruda AMV, Costa LLM (2019) Estimating sensible heat loss in laying hens through thermal imaging Computers and Electronics in Agriculture 166:1-5.

Spurio RS, Soares AL, Carvalho RH, Silveira-Júnior V, Grespan M, Oba A, Shimokomaki M (2016) Improving transporte container design to reduce broiler chicken PSE (Pale, soft, exudative) meat in Brazil. Animal Science Journal 87:277-283.

Pinheiro DG (2015) Molhamento da carga como método de atenuação do estresse térmico durante o transporte de frangos vivos. Dissertação, Universidade Federal do Ceará.

Vinco LJ, Archetti IL, Giacomelli S, Lombardi G (2016). Influence of crate height on the welfare of broilers during transport. Journal of Veterinary Behaviour 14:28-33.

Webster AJF, Tuddenham A, Saville CA, Scott GB (1992). Thermal stress on chickens in transit. British Poultry Science 34:267-277. 